\title{
Estimating sodium intake from spot urine samples at population level: a validation and application study in French adults
}

\author{
Elise Emeville ${ }^{1}$, Camille Lassale ${ }^{2,3}$, Katia Castetbon ${ }^{4}$, Valérie Deschamps ${ }^{5}$, Benoît Salanave ${ }^{5}$ \\ Michel Vernay ${ }^{6}$, Dorra Guergour ${ }^{7}$, Patrice Faure ${ }^{7,8}$, Serge Hercberg ${ }^{5,9,10}$, Pilar Galan ${ }^{9}$, \\ Emmanuelle Kesse-Guyot ${ }^{9}$ and Charlotte Verdot ${ }^{5 *}$ \\ ${ }^{1}$ Observatoire de la Santé de Guadeloupe (ORSaG), Baie-Mahault, France \\ ${ }^{2}$ Department of Epidemiology and Public Health, University College London, London WC1E $7 H B$, UK \\ ${ }^{3}$ Program of Epidemiology and Public Health, Hospital del Mar Medical Research Institute (IMIM), O8024 Barcelona, Spain \\ ${ }^{4}$ Université libre de Bruxelles, Ecole de Santé Publique, Centre de Recherche en Epidémiologie, Biostatistique, et Recherche \\ Clinique, B-1070 Bruxelles, Belgium \\ ${ }^{5}$ Nutrition Surveillance and Epidemiology Team, Santé publique France, University Paris 13, Centre of Research in \\ Epidemiology and StatisticS (CRESS UMR1153) - University of Paris, Bobigny F-93017, France \\ ${ }^{6}$ Santé publique France, Regions Division, Saint-Maurice, France \\ ${ }^{7}$ Platform of Biochemistry, University Hospital of Grenoble, Grenoble F-38700, France \\ ${ }^{8}$ University Grenoble Alpes, HP2 Laboratory, Grenoble F-38058, France \\ ${ }^{9}$ Nutritional Epidemiology Research Team, INSERM U1153, INRA U1125, CNAM, University Paris 13, Centre of Research in \\ Epidemiology and StatisticS (CRESS UMR1153) - University of Paris, Bobigny F-93017, France \\ ${ }^{10}$ Public Health Department, Avicenne Hospital, University Paris 13, Bobigny F-93017, France
}

(Submitted 20 November 2018 - Final revision received 1 March 2019 - Accepted 5 April 2019; First published online 16 July 2019)

\section{Abstract}

The aim of this study was to assess the validity of the predictive INTERSALT equation using spot urine samples to estimate 24-h urinary Na (24-hUNa) excretion and daily $\mathrm{Na}$ intake among the French adult population. Among 193 French adults ('validation sample'), we assessed the validity by comparing predicted 24-hUNa excretion from spot urine and measured 24-hUNa excretion from 24-h urine collections. Spearman correlation coefficients and Bland-Altman plots were used and we calculated calibration coefficients. In a nationally representative sample of 1720 French adults ('application sample'), the calibrated predictive equation was then applied to the spot urine Na values to estimate 24-hUNa excretion and daily $\mathrm{Na}$ intake. In that sample, predicted $\mathrm{Na}$ intake was compared with that estimated from 24-h dietary recalls. Results were adjusted and corrected using calibration coefficients. In the validation sample, the measured 24-hUNa excretion was on average $14 \%$ higher than the predicted $24-\mathrm{hUNa}(+13 \%$ for men and $+16 \%$ for women). Correlation between measured and predicted $24-\mathrm{hUNa}$ excretion was moderate (Spearman $r$ 0.42), and the Bland-Altman plots showed underestimation at lower excretion level and overestimation at higher level. In the application study, estimated daily salt intake was $8.0 \mathrm{~g} / \mathrm{d}$ using dietary recalls, $8.1 \mathrm{~g} / \mathrm{d}$ using predicted INTERSALT equation and $9.3 \mathrm{~g} / \mathrm{d}$ after applying calibration coefficients calculated in the validation study. Despite overall underestimation of 24-hUNa excretion by spot urinary $\mathrm{Na}$, the use of predictive INTERSALT equation remains an acceptable alternative in monitoring global Na intake/excreted in the French population but its use is not advised at the individual level.

Key words: Salt intake: Urinary sodium excretion: Spot urine samples: Predictive INTERSALT equation

$\mathrm{Na}$ is an essential nutrient, mainly provided by the salt contained in foods and table salt used as condiment. Nevertheless, excessive $\mathrm{Na}$ consumption has adverse health outcomes, including high blood pressure and an increased risk of CVD and stroke ${ }^{(1-6)}$. The average level of $\mathrm{Na}$ consumption has been estimated to be $3.95 \mathrm{~g} / \mathrm{d}$ (equivalent to $10 \mathrm{~g}$ of salt) in sixty-six countries worldwide ${ }^{(7)}$, which is almost twice as much the amount recommended by the WHO $(<2 \mathrm{~g} / \mathrm{d} \text { of } \mathrm{Na})^{(8)}$. Therefore, the reduction of population salt intake is a public health priority. However, quantification of discretionary salt (added by individuals) is particularly difficult in diet surveys ${ }^{(9)}$ and accurate monitoring of salt intake can be challenging.

As approximately $90 \%$ of daily $\mathrm{Na}$ intake is excreted in the urine throughout the day ${ }^{(10)}, 24$-h urine collection is considered

Abbreviations: 24-hUNa, 24-h urinary Na; ENNS, Etude Nationale Nutrition Santé.

* Corresponding author: Dr C. Verdot, email charlotte.verdot@univ-paris13.fr 
as the 'gold standard' method for assessing Na consumption ${ }^{(9,11)}$. However, urine collections over a 24 -h period are difficult to obtain, as this method is logistic and cost intensive as well as burdensome for participants, limiting its use in large-scale surveys and epidemiological studies ${ }^{(12,13)}$. To overcome these difficulties, alternative methods have been proposed, such as the use of spot and timed urine samples, which are easier and cheaper to collect, and better accepted by participants. Thereby, different equations have been developed to predict 24-h urinary $\mathrm{Na}$ (24-hUNa) excretion from spot urine samples ${ }^{(14-21)}$. While most of these studies have been conducted in Asian populations ${ }^{(14,15,21)}$, recent validation studies have shown that the INTERSALT equation ${ }^{(16)}$ provided the least biased predictions in Western population ${ }^{(18-20)}$. This sex-specific equation takes into account $\mathrm{Na}, \mathrm{K}$ and creatinine concentrations from spot urine samples, age, sex, geographical region and BMI of the individuals

The use of predictive equations from spot urine samples exhibits many advantages and appears promising for monitoring population $\mathrm{Na}$ intake, yet this method remains controversial as results differ depending on the studies and populations. Some previous studies concluded, however, that it may be a useful tool for monitoring 24-hUNa excretion at the population level, but predictions perform poorly at the individual level, due to day-to-day within-person and within-day variability of Na excretion $^{(13,15,18-25)}$. Therefore, accuracy and suitability of predicting equations need improvement. Most studies so far have focused on the timing of urine collection and on the benefits of using multiple spot urine samples to produce estimates ${ }^{(16,23,25-29)}$. Some authors also recommended the use of 'population-specific' equations or study-specific calibrations against 24-h urine collections to ensure the validity of spot urine samples to predict population $\mathrm{Na}$ intake $(12,16,22)$

Our study has four objectives: (1) validation, whereby predicted 24-hUNa excretion from spot urine obtained by INTERSALT equation is compared with measured 24-hUNa excretion; (2) calibration on French data of the INTERSALT equation; (3) assessment of the original and calibrated INTERSALT equation to assess salt intake of French adults and (4) comparison of predicted salt intake from spot urine samples with self-reported salt intake from 24-h dietary recalls. Objectives (1) and (2) were conducted in a validation study of 193 healthy volunteers, and objectives (3) and (4) on a nationally representative sample of 1720 French adults.

\section{Methods \\ Validation study}

Study population. The study population included volunteers from a randomly selected sample of NutriNet-Santé study participants, involved in the Dietary Validation Study ${ }^{(30)}$. The NutriNetSanté study (ClinicalTrials.gov identifier: NCT03335644) is an ongoing web-based cohort launched in France in 2009, which included volunteers over 18 years old. Details of aims and methods have been described elsewhere ${ }^{(31)}$. The Dietary Validation Study was conducted in 2012-2013 to investigate the validity of a web-based, self-administered dietary record tool against urinary biomarkers ${ }^{(30)}$. It included a randomly selected sample of 199 participants of the NutriNet-Santé study, stratified by sex, age ( $<45$ years, $>45$ years) and educational level (primary and secondary up to some college, university graduate). Participants were excluded if they were pregnant, had a known history of heart failure or diabetes. The sample size was calculated in accordance with the main objective of the Dietary Validation Study, that is 200 participants were needed to detect correlation coefficients greater than or equal to $0 \cdot 17$ at the $5 \%$ significance level and with $80 \%$ power. This sample size was also sufficient to detect a difference of $1 \mathrm{~g}$ around a mean of $8 \mathrm{~g}$ of salt intake per $\mathrm{d}$ compared with an average population of 2000 individuals (at the 5\% significance level and with $80 \%$ power). The protocol of the study was approved by the Consultation Committee for the Protection of Participants in Biomedical Research of Paris Saint-Louis (no. 2011/22) and the French National Information and Citizen Freedom Committee (DR-2012-467). Participants provided written informed consent.

Study design. Data were collected during two visits performed in a clinical centre (Hôtel Dieu Hospital, Paris), both in a fasting state. At the first visit, anthropometric and clinical measurements were taken (height, weight, blood pressure) and participants were given instructions for the 24-h urine collection. Approximately 3 weeks later, a second visit was realised with the same clinical examination. At each of the two visits, a morning fasting spot urine was collected at the clinical centre. Between the two visits, three 24-h dietary records were completed and two 24-h urine samples were collected per participant. More details of material and methods are available elsewhere ${ }^{(30)}$.

24-h urine collection. A written explanation of the 24-h urine collection process was provided to all participants with material necessary for collection. Volunteers were instructed to discard the first urine of the day of collection, and then to collect all urine passed during the next $24 \mathrm{~h}$, including the first urine the following morning. They were given para-aminobenzoic acid pills to take throughout the day to check completeness of the urine collection. Participants had to record the start and finish times of urine collection, the time at which para-aminobenzoic acid pills were taken, any missing void (urine discarded during the collection) and medications taken during the $24-\mathrm{h}$ period. The urine container was kept at room temperature in a dark place. Urine samples were processed less than $12 \mathrm{~h}$ after the end of the collection: they were weighed, carefully mixed and aliquoted into $1 \mathrm{ml}$ samples and stored at $-80^{\circ} \mathrm{C}$. Urinary electrolyte levels in the two 24-h urine collections and in the two spot urine samples were analysed in the laboratory of the biochemistry platform of the University Hospital (CHU) of Grenoble. Na and K concentrations were measured by ion-selective electrodes (Siemens Dimension Vista), and creatinine concentration was measured by alkaline picrate kinetic (Siemens Dimension Vista). The intra-assay CV for all three measures were $<3 \%$.

\section{Application study}

Study sample. The study sample comprised all adults aged 18-74 years included in the French Nutrition and Health 
Survey (Etude Nationale Nutrition Santé, ENNS). The ENNS is a nationwide survey conducted in 2006-2007 to describe dietary intake, physical activity and nutritional status in a nationally representative sample of adults and children living in France. The protocol was approved by the Ethical Committee (Hôpital Cochin, Paris, no. 2264), the Consultative Committee on Information Treatment of the Ministry of Research and the French Data Protection Authority (authorisation no. 905481). All participants signed informed consents.

Study design. The ENNS is a cross-sectional study using a multistage sampling design, already described in detail elsewhere ${ }^{(32)}$. In brief, data collection included a questionnaire survey, three 24-h dietary recalls and a health examination with clinical and biochemical markers measurements for each participant. Social and demographic characteristics and physical activity were collected at home via face-to-face interview. Clinical (height, weight, blood pressure) and biochemical markers measurements were collected at health examination centres of National Health Insurance system, or at home with a nurse (if subjects did not want to go to a health centre). Recruitment was carried out for 1 year to take into account the seasonality of the diet.

Dietary recalls. Dietary intake was assessed using three non-consecutive 24-h dietary recalls, one of them being during the weekend, randomly distributed within a period of 2 weeks. Trained dietitians asked participants to describe everything they ate or drank the day before the interview, from midnight to midnight. Subjects gave information according to a precise and standard methodology detailed elsewhere ${ }^{(32)}$. Information on discretionary salt (added in cooking or at the table) was specifically collected, that is a summary of all food items consumed was provided, which participants had to review and describe if additional salt was consumed, and if so, in what quantity (household units or g).

Urine samples. On the day of health examination, participants were asked to collect first-morning urine and store it at $+4^{\circ} \mathrm{C}$. Samples were then carried up to the field laboratories within $4 \mathrm{~h}$ after collection in frozen containers and stored at $-80^{\circ} \mathrm{C}$ until their transport to central laboratory at the end of the fieldwork. $\mathrm{Na}, \mathrm{K}$ and creatinine concentrations were measured in the same laboratory using the same methods and materials as for the validation study. The intra-assay CV for all three measures were $<3 \%$.

\section{Statistical methods}

Covariates. BMI was calculated as weight $(\mathrm{kg}) / \mathrm{height}^{2}\left(\mathrm{~m}^{2}\right)$. The reference values used to define BMI classes (underweight $<18.5 \mathrm{~kg} / \mathrm{m}^{2}$, normal $18.5-24.9 \mathrm{~kg} / \mathrm{m}^{2}$, overweight $25 \cdot 0-29.9$ $\mathrm{kg} / \mathrm{m}^{2}$ and obese $\geq 30 \cdot 0 \mathrm{~kg} / \mathrm{m}^{2}$ ) were those recommended by the $\mathrm{WHO}^{(33)}$. Tobacco status was categorised as: never smoke, former smoker and current smoker; alcohol use as abstainers and consumers (even occasional) and educational level as low (up to high school), medium (some college) and high (university graduate).
Characteristics of participants in the validation study were compared using $t$ tests or $\chi^{2}$ tests, as appropriate. Analyses in the application study (ENNS) were weighted taking into account individual probabilities of inclusion, seasonal period of data collection and calibration based on national census data. Characteristics of participants in the application study were compared using tests for complex survey designs: $t$ tests for continuous variables (adjusted Wald $F$ statistic) and $\chi^{2}$ tests for frequencies (Rao and Scott second-order corrected Pearson statistic).

Validation study. Twenty-four-hour urine collections were determined as valid if collection time was between 22 and $26 \mathrm{~h}$, urine volume was $\geq 500 \mathrm{ml}$, estimated volume missed void was less than $5 \%$ of the total volume and creatinine was $>10 \mathrm{mg} / \mathrm{kg}$ for women or $>15 \mathrm{mg} / \mathrm{kg}$ for men.

The mean 24-hUNa excretion $(\mathrm{mmol} / \mathrm{d})$ from the two 24-h urine collections and the mean $\mathrm{Na}, \mathrm{K}$ and creatinine concentrations $(\mathrm{mmol} / \mathrm{l})$ from the two spot samples were calculated. If only one spot urine sample was collected or only one 24-h urine collection was considered as valid, the only available value was used. Due to the skewed distribution, geometric means (and $95 \% \mathrm{CI}$ ) were presented.

The INTERSALT formula developed in North American and European populations ${ }^{(16)}$ was used to estimate 24-hUNa excretion from spot urine samples. The following sex-specific equations for Western Europe were used:

For men:

Predicted 24-hUNa excretion $(\mathrm{mmol} / \mathrm{d})=17 \cdot 05+(0.46 \times$ spot $\mathrm{Na}(\mathrm{mmol} / \mathrm{l}))-(2.75 \times$ spot creatinine $(\mathrm{mmol} / \mathrm{l}))-(0 \cdot 13 \times$ spot $\mathrm{K}$ $(\mathrm{mmol} / \mathrm{l}))+\left(4 \cdot 10 \times\right.$ BMI $\left.\left(\mathrm{kg} / \mathrm{m}^{2}\right)\right)+(0 \cdot 26 \times$ age $($ years $))$.

For women:

Predicted 24-hUNa excretion $(\mathrm{mmol} / \mathrm{d})=12 \cdot 82+(0 \cdot 34 \times$ spot $\mathrm{Na}(\mathrm{mmol} / \mathrm{l}))-(2 \cdot 16 \times$ spot creatinine $(\mathrm{mmol} / \mathrm{l}))-(0 \cdot 09 \times$ spot $\mathrm{K}$ $(\mathrm{mmol} / \mathrm{l}))+\left(2.39 \times \mathrm{BMI}\left(\mathrm{kg} / \mathrm{m}^{2}\right)\right)+(2.35 \times$ age $($ years $))-(0.03 \times$ $\operatorname{age}^{2}$ (years)).

The measured and predicted 24-hUNa excretions were compared by the Mann-Whitney $U$ test.

Spearman correlation coefficients were calculated to examine their relationship for the total sample and separately for men and women.

Bland-Altman plots ${ }^{(34)}$ were used to validate the agreement between measured and predicted 24-hUNa excretion. The degree of bias (i.e. mean difference between measured and predicted 24-hUNa excretion) and $95 \%$ limits of agreement were estimated.

The percentage error ${ }^{(35)}$ was calculated as: $1.96 \times(\mathrm{SD}$ of the difference between measured and predicted 24-hUNa excretion) $/($ mean of measured $24-\mathrm{hUNa}$ excretion $) \times 100$.

Finally, the ratio of the geometric means of measured to predicted 24-hUNa excretions was used to quantify the difference between measure and prediction: a ratio of 1 representing no difference between measured and predicted 24-hUNa excretion; a ratio $<1$ reporting an overestimation of the prediction and a ratio $>1$ an underestimation. This ratio, expressed as a percentage, was then used to calibrate the predictive INTERSALT equation on the French adult population and thus provides a corrected equation. 
Table 1. Baseline characteristics of participants in the validation study ( $n$ 193)

(Mean values and standard deviations; percentages and $95 \%$ confidence intervals)

\begin{tabular}{|c|c|c|c|c|c|c|c|}
\hline & \multicolumn{2}{|c|}{ All $(n 193)$} & \multicolumn{2}{|c|}{ Men $(n$ 102) } & \multicolumn{2}{|c|}{ Women ( $n$ 91) } & \multirow[b]{2}{*}{$P^{\star}$} \\
\hline & $\%$ & $95 \% \mathrm{Cl}$ & $\%$ & $95 \% \mathrm{Cl}$ & $\%$ & $95 \% \mathrm{Cl}$ & \\
\hline Age (years) & & & & & & & 0.92 \\
\hline Mean & \multicolumn{2}{|c|}{$50 \cdot 1$} & \multicolumn{2}{|c|}{$50 \cdot 0$} & \multicolumn{2}{|c|}{$50 \cdot 3$} & \\
\hline SD & \multicolumn{2}{|c|}{$16 \cdot 5$} & \multicolumn{2}{|c|}{$16 \cdot 2$} & \multicolumn{2}{|c|}{$16 \cdot 9$} & \\
\hline Weight (kg) & & & & & & & $<0.001$ \\
\hline Mean & \multicolumn{2}{|c|}{$69 \cdot 0$} & \multicolumn{2}{|c|}{74.8} & \multicolumn{2}{|c|}{$62 \cdot 4$} & \\
\hline $\mathrm{SD}$ & \multicolumn{2}{|c|}{$12 \cdot 4$} & \multicolumn{2}{|c|}{$10 \cdot 8$} & \multicolumn{2}{|c|}{$10 \cdot 7$} & \\
\hline Height (cm) & \multirow{2}{*}{\multicolumn{2}{|c|}{169.7}} & \multirow{2}{*}{\multicolumn{2}{|c|}{$176 \cdot 1$}} & \multirow{2}{*}{\multicolumn{2}{|c|}{$162 \cdot 5$}} & $<0.001$ \\
\hline Mean & & & & & & & \\
\hline SD & \multicolumn{2}{|c|}{9.5} & \multicolumn{2}{|c|}{$7 \cdot 1$} & \multicolumn{2}{|c|}{$6 \cdot 1$} & \\
\hline $\mathrm{BMI}\left(\mathrm{kg} / \mathrm{m}^{2}\right)$ & & & & & & & 0.39 \\
\hline Mean & \multirow{2}{*}{\multicolumn{2}{|c|}{$\begin{array}{r}23 \cdot 9 \\
3.5\end{array}$}} & \multicolumn{2}{|c|}{$24 \cdot 1$} & \multicolumn{2}{|c|}{$23 \cdot 7$} & \\
\hline SD & & & \multicolumn{2}{|c|}{2.9} & \multicolumn{2}{|c|}{$4 \cdot 1$} & \\
\hline \multicolumn{6}{|l|}{ BMI $\left(\mathrm{kg} / \mathrm{m}^{2}\right)$} & & \\
\hline Underweight $(<18.5)$ & $4 \cdot 2$ & $2 \cdot 1,8 \cdot 1$ & 1.0 & $0 \cdot 1,6 \cdot 8$ & $7 \cdot 7$ & $3 \cdot 7,15 \cdot 5$ & \\
\hline Normal (18.5-24.9) & $62 \cdot 7$ & $55 \cdot 6,69 \cdot 3$ & $60 \cdot 8$ & $50.8,69.9$ & $64 \cdot 8$ & $54 \cdot 3,74 \cdot 1$ & 0.001 \\
\hline Overweight (25-29.9) & $26 \cdot 4$ & $20 \cdot 6,33 \cdot 2$ & $35 \cdot 3$ & $26 \cdot 5,45 \cdot 2$ & $16 \cdot 5$ & $10 \cdot 1,25 \cdot 8$ & \\
\hline Obese $(\geq 30)$ & $6 \cdot 7$ & $3 \cdot 9,11 \cdot 3$ & $2 \cdot 9$ & $0.9,8.9$ & $11 \cdot 0$ & $5 \cdot 9,19 \cdot 4$ & \\
\hline \multicolumn{8}{|l|}{ Tobacco smoking } \\
\hline Never & $53 \cdot 1$ & $46 \cdot 0,60 \cdot 1$ & $52 \cdot 5$ & $42 \cdot 6,62 \cdot 2$ & 53.8 & $43 \cdot 4,64 \cdot 0$ & \\
\hline Former & $32 \cdot 8$ & $26 \cdot 5,39 \cdot 8$ & 36.6 & $27 \cdot 7,46 \cdot 6$ & $28 \cdot 6$ & $20 \cdot 1,38.9$ & 0.29 \\
\hline Current & $14 \cdot 1$ & $9 \cdot 8,19.8$ & $10 \cdot 9$ & $6 \cdot 1,18 \cdot 8$ & $17 \cdot 6$ & $11 \cdot 0,27 \cdot 0$ & \\
\hline \multicolumn{8}{|l|}{ Education } \\
\hline Up to high school & 19.7 & $14 \cdot 6,26 \cdot 0$ & 18.6 & $12 \cdot 1,27 \cdot 5$ & 20.9 & $13 \cdot 6,30 \cdot 6$ & \\
\hline High school & $30 \cdot 0$ & $24 \cdot 0,37 \cdot 0$ & $31 \cdot 4$ & $23 \cdot 0,41 \cdot 2$ & $28 \cdot 6$ & $20 \cdot 1,38 \cdot 9$ & 0.88 \\
\hline University graduate & $50 \cdot 3$ & $43 \cdot 2,57 \cdot 3$ & $50 \cdot 0$ & $40 \cdot 3,59 \cdot 7$ & 50.5 & $40 \cdot 2,60 \cdot 8$ & \\
\hline
\end{tabular}

${ }^{*} P$ value for the difference between men and women was calculated by $t$ test or $\chi^{2}$ test as appropriate.

Application study. A first estimation of daily $\mathrm{Na}$ intake was realised from the 24-h dietary recalls. To get the salt equivalent, $\mathrm{Na}$ intake was multiplied by $2 \cdot 54$.

A second estimation of daily $\mathrm{Na}$ intake was realised from urinary spot samples: 24-hUNa excretion was estimated from predictive INTERSALT equation, and, assuming that approximately $93 \%$ of $\mathrm{Na}$ intake is urinary excreted in $24 \mathrm{~h}^{(10)}$, predicted daily $\mathrm{Na}$ intake was then calculated as follows:

Predicted $\mathrm{Na}_{\text {intake }}(\mathrm{mg} / \mathrm{d})=24-\mathrm{hUNa} \mathrm{excret}_{\text {ex }}(\mathrm{mmol} / \mathrm{d}) \times 23$ (conversion factor from mmol of $\mathrm{Na}$ to $\mathrm{mg}$ )/0.93.

The two Na intake estimations (from dietary recalls and from INTERSALT equation) were compared by $t$ tests and the difference was quantified by the ratio of the two values and expressed as a percentage.

Finally, all predicted values (24-hUNa excretion, predicted $\mathrm{Na}$ intake and salt equivalent) were recalculated by applying the calibration coefficients obtained in the validation study.

All analyses were carried out with Stata $₫$ software version 14 (StataCorp). All tests were two-tailed, and $P$ values $<0.05$ were considered statistically significant. Survey data analyses (in the application study) were realised using the 'svyset' function (for the declaration of the complex sampling scheme) and 'svy:' option.

\section{Results}

\section{Validation study}

Both 24-h urine collections were invalid for four women and two men, hence six participants were excluded from the analysis.
The validation sample was then composed of 102 men $(52 \cdot 8 \%)$ and 91 women ( $47 \cdot 2 \%$; Table 1$)$. Mean age was $50 \cdot 1$ (sD 16.5 ) years and mean BMI was 23.9 (SD 3.5$) \mathrm{kg} / \mathrm{m}^{2}$. Spot urine samples concentration of electrolytes and measured and predicted 24-hUNa excretions are presented in Table 2. The geometric mean $\mathrm{Na}$ concentration was $72.4 \mathrm{mmol} / \mathrm{l}$ for men and $63.5 \mathrm{mmol} / \mathrm{l}$ for women. A statistically significant difference was observed between men and women for creatinine urinary concentration but not for $\mathrm{Na}$ and $\mathrm{K}$. The geometric mean of measured 24-hUNa excretion was $123.3 \mathrm{mmol} / \mathrm{d}(2836 \mathrm{mg} / \mathrm{d})$ and the one predicted was $108.0 \mathrm{mmol} / \mathrm{d}(2484 \mathrm{mg} / \mathrm{d})$. The predicted 24-hUNa excretion was significantly different from the measured 24-hUNa $(P<0.001)$. Urinary $\mathrm{Na}$ excretion was significantly higher in men than in women $(P<0.001)$ for both 24 -hUNa excretions derived from direct measurement and prediction. Correlation between measured and predicted 24-hUNa excretions was moderate in men $(r 0.43 ; P<0.001)$ and weak, albeit statistically significant $(r 0.34 ; P<0.001)$ in women (Table 3$)$.

The agreement between the measured 24-hUNa excretion and the prediction from spot urine samples by the INTERSALT equation was analysed by Bland-Altman plots (Fig. 1). The plots showed an underestimation at lower excretion level and overestimation at higher level. The degree of bias at the group level was $19.2 \mathrm{mmol} / \mathrm{d}(442 \mathrm{mg} / \mathrm{d})$ and the agreement limits are from 61.4 to $99.7 \mathrm{mmol} / \mathrm{d}$ ( -1412 to $2293 \mathrm{mg} / \mathrm{d}$ ) (Table 3 ). The ratio of geometric means indicates that the measured 24 -hUNa excretion was on average $14 \%$ higher than the predicted ( $13 \%$ in men and $16 \%$ in women; Table 3 ), therefore that the equation underestimated the Na excretion. Furthermore, the percentage error was $60 \cdot 4 \%$ (equivalent for men and women). 
Table 2. Spot urine samples concentration of electrolytes and 24-h urinary sodium (24-hUNa) excretion (measured and predicted) in the validation study ( $n$ 193)

(Geometric means and $95 \%$ confidence intervals)

\begin{tabular}{|c|c|c|c|c|c|c|c|}
\hline & \multicolumn{2}{|c|}{ All $(n$ 193) } & \multicolumn{2}{|c|}{ Men $(n$ 102) } & \multicolumn{2}{|c|}{ Women ( $n$ 91) } & \multirow[b]{2}{*}{$P \dagger$} \\
\hline & Geometric mean & $95 \% \mathrm{Cl}$ & Geometric mean & $95 \% \mathrm{Cl}$ & Geometric mean & $95 \% \mathrm{Cl}$ & \\
\hline \multicolumn{8}{|c|}{ Spot urine samples concentration } \\
\hline $\mathrm{Na}(\mathrm{mmol} / \mathrm{l})$ & 68.1 & $63 \cdot 1,73 \cdot 3$ & $72 \cdot 4$ & $65.7,79.8$ & 63.5 & $56 \cdot 5,71 \cdot 2$ & 0.07 \\
\hline $\mathrm{K}(\mathrm{mmol} / \mathrm{l})$ & 54.5 & $50 \cdot 9,58.3$ & 53.7 & $49 \cdot 1,58 \cdot 7$ & $55 \cdot 3$ & $49.8,61 \cdot 4$ & 0.52 \\
\hline Creatinine $(\mathrm{mmol} / \mathrm{l})$ & 9.8 & $9 \cdot 0,10 \cdot 8$ & $10 \cdot 9$ & $9 \cdot 7,12 \cdot 3$ & $8 \cdot 7$ & $7 \cdot 6,10 \cdot 0$ & 0.02 \\
\hline \multicolumn{8}{|l|}{ 24-hUNa excretion } \\
\hline Measured $(\mathrm{mmol} / \mathrm{d})$ & $123 \cdot 3$ & $117 \cdot 3,129 \cdot 6$ & 134.2 & $125 \cdot 3,143 \cdot 7$ & $112 \cdot 1$ & $104 \cdot 6,120 \cdot 1$ & $<0.001$ \\
\hline Predicted $(\mathrm{mmol} / \mathrm{d})$ & $108 \cdot 0^{\star * *}$ & $104 \cdot 0,112 \cdot 2$ & $119 \cdot 2^{\star \star \star}$ & $113 \cdot 3,125 \cdot 5$ & $96 \cdot 8^{\star \star \star}$ & $92 \cdot 2,101 \cdot 6$ & $<0.001$ \\
\hline
\end{tabular}

${ }_{* \star *}$ Mean value was significantly different from that for 24-hUNa measured $(P<0.001$; Mann-Whitney $U$ test $)$.

$\dagger P$ value for the difference between men and women was calculated by the Mann-Whitney $U$ test.

Table 3. Agreement between measured and predicted 24-h urinary sodium excretion in the validation study ( $n$ 193)

(Spearman correlation coefficients; mean values and standard deviations; $95 \%$ limits of agreement)

\begin{tabular}{|c|c|c|c|}
\hline & $\begin{array}{c}\text { All } \\
(n \text { 193) }\end{array}$ & $\begin{array}{c}\text { Men } \\
(n \text { 102) }\end{array}$ & $\begin{array}{l}\text { Women } \\
(n 91)\end{array}$ \\
\hline Spearman correlation coefficient & $0.42^{* * *}$ & $0.43^{\star \star *}$ & $0.34^{\star \star *}$ \\
\hline \multicolumn{4}{|l|}{ Difference (measured - predicted) $(\mathrm{mmol} / \mathrm{d})$} \\
\hline Mean & $19 \cdot 2$ & $19 \cdot 3$ & $19 \cdot 0$ \\
\hline SD & $40 \cdot 3$ & $44 \cdot 0$ & $36 \cdot 0$ \\
\hline $95 \%$ limits of agreement $(\mathrm{mmol} / \mathrm{d})$ & $\begin{array}{c}-61.4 \\
99.7\end{array}$ & $\begin{array}{c}-68.6 \\
107.2\end{array}$ & $\begin{array}{c}-52.9 \\
90.9\end{array}$ \\
\hline \multicolumn{4}{|l|}{ Ratio (measured/predicted) } \\
\hline Mean & $1 \cdot 14$ & $1 \cdot 13$ & $1 \cdot 16$ \\
\hline SD & 0.45 & 0.48 & 0.41 \\
\hline
\end{tabular}

${ }_{\star \star *} P$ value for the Spearman correlation test was statistically significant $(P<0.001)$.

\section{Application study}

Among the 2102 adults included in the ENNS study who participated in the biochemical part, 1720 (81.8\%) had complete spot urine samples (a specific weighting strategy based on census data has been realised for this subpopulation). Women represented $50.3 \%$ of the weighted population. The weighted mean age was $45 \cdot 2$ years for total population, with women older than men ( $46.0 v .44 .5$ years; Table 4$)$.

The weighted mean of $\mathrm{Na}, \mathrm{K}$ and creatinine were $93.1 \mathrm{mmol} / \mathrm{l}$, $31.4 \mathrm{mmol} / \mathrm{l}$ and $11.0 \mathrm{mmol} / \mathrm{l}$, respectively (Table 5). Concentrations were higher in men than in women. The mean $\mathrm{Na}$ intake measured from the 24-h dietary recalls was $3159 \mathrm{mg} /$ $\mathrm{d}(3681 \mathrm{mg} / \mathrm{d}$ for men and $2642 \mathrm{mg} / \mathrm{d}$ for women), whereas the mean predicted $\mathrm{Na}$ intake by the INTERSALT equation was $3188 \mathrm{mg} / \mathrm{d}$ (3480 mg/d for men and $2898 \mathrm{mg} / \mathrm{d}$ for women). $\mathrm{Na}$ intake reported in the 24-h dietary recalls was greater than that estimated by the INTERSALT equation by $+5.5 \%$ in men $(P<0 \cdot 01)$, but lower in women $(-9.7 \% ; P<0.001)$.

When the INTERSALT calculated values were corrected using sex-specific calibration coefficients calculated in the validation study ( $+13 \%$ for men and $+16 \%$ for women), the predicted $\mathrm{Na}$ intake was $3646 \mathrm{mg} / \mathrm{d}$ (3932 mg/d for men and $3362 \mathrm{mg} / \mathrm{d}$ for women), equivalent to $9.3 \mathrm{~g}$ of salt consumed daily ( $10.0 \mathrm{~g}$ for men and $8.5 \mathrm{~g}$ for women). Therefore, compared with the calibrated predicted values, $\mathrm{Na}$ intake calculated from dietary recalls was underestimated by $15.4 \%$ (6.8\% among men and $27 \cdot 2 \%$ among women).

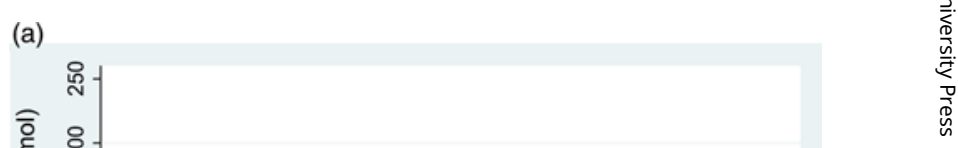

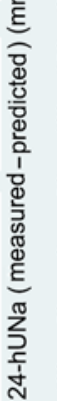

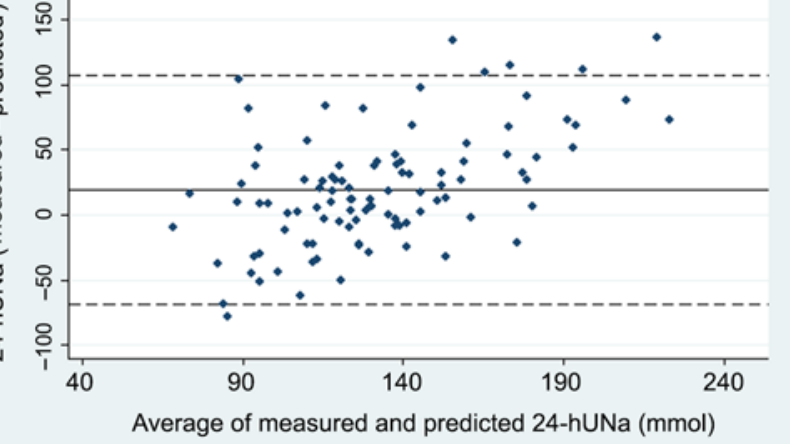

(b)

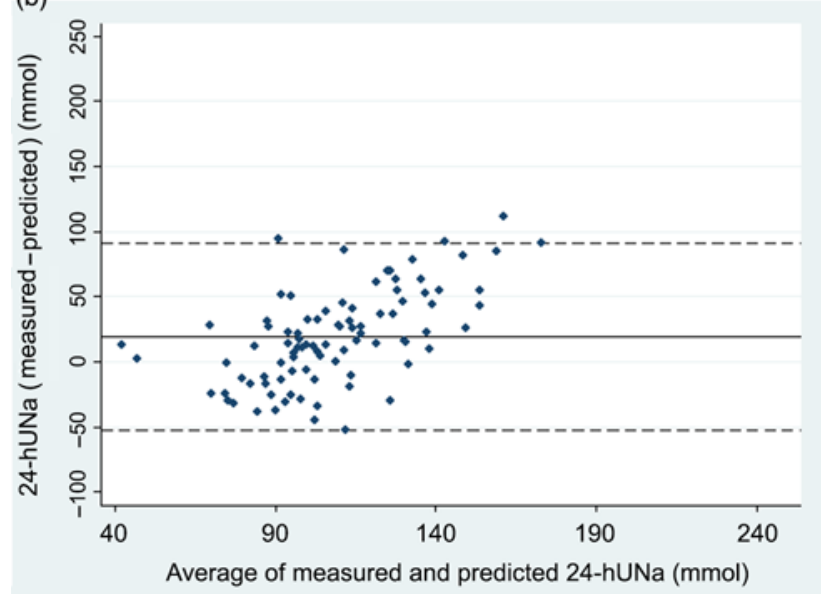

Fig. 1. Bland-Altman plots for agreement between measured 24-h urinary sodium (24-hUNa) excretion and predicted 24-hUNa excretion from spot urine samples and INTERSALT equation in the validation study in 102 men (a) and 91 women (b). The solid line represents the mean of paired difference and the dashed lines represent the $95 \%$ limits of agreement (mean $\pm 2 \mathrm{sD}$ ).

\section{Discussion}

This study assessed the validity of the predictive INTERSALT equation to estimate the 24-hUNa excretion from spot urine samples and produced calibration coefficients for the French adult population. 
Table 4. Baseline characteristics of participants in the application study ( $n 1720)$

(Mean values and standard deviations; percentages and $95 \%$ confidence intervals)

\begin{tabular}{|c|c|c|c|c|c|c|c|}
\hline & \multicolumn{2}{|c|}{ All $(n$ 1720) } & \multicolumn{2}{|c|}{ Men ( $n$ 662) } & \multicolumn{2}{|c|}{ Women $(n$ 1058) } & \multirow[b]{2}{*}{$P^{*}$} \\
\hline & $\%$ & $95 \% \mathrm{Cl}$ & $\%$ & $95 \% \mathrm{Cl}$ & $\%$ & $95 \% \mathrm{Cl}$ & \\
\hline Age (years) & & & & & & & 0.21 \\
\hline Mean & \multicolumn{2}{|c|}{$45 \cdot 2$} & \multicolumn{2}{|c|}{44.5} & \multicolumn{2}{|c|}{$46 \cdot 0$} & \\
\hline SD & \multicolumn{2}{|c|}{0.6} & \multicolumn{2}{|c|}{0.9} & \multicolumn{2}{|c|}{0.7} & \\
\hline Weight (kg) & & & & & & & $<0.001$ \\
\hline Mean & \multicolumn{2}{|c|}{$71 \cdot 8$} & \multicolumn{2}{|c|}{$78 \cdot 1$} & \multicolumn{2}{|c|}{$65 \cdot 6$} & \\
\hline SD & \multicolumn{2}{|c|}{0.5} & \multicolumn{2}{|c|}{0.7} & \multicolumn{2}{|c|}{0.6} & \\
\hline Height (cm) & & & & & & & $<0.001$ \\
\hline Mean & \multicolumn{2}{|c|}{$168 \cdot 2$} & \multicolumn{2}{|c|}{$174 \cdot 6$} & \multicolumn{2}{|c|}{$161 \cdot 8$} & \\
\hline SD & \multicolumn{2}{|c|}{0.3} & \multicolumn{2}{|c|}{0.4} & \multicolumn{2}{|c|}{0.3} & \\
\hline BMI $\left(\mathrm{kg} / \mathrm{m}^{2}\right)$ & & & & & & & 0.08 \\
\hline Mean & \multicolumn{2}{|c|}{$25 \cdot 4$} & \multicolumn{2}{|c|}{$25 \cdot 6$} & \multicolumn{2}{|c|}{$25 \cdot 1$} & \\
\hline SD & \multicolumn{2}{|c|}{0.2} & \multicolumn{2}{|c|}{0.2} & \multicolumn{2}{|c|}{0.2} & \\
\hline \multicolumn{8}{|l|}{ BMI $\left(\mathrm{kg} / \mathrm{m}^{2}\right)$} \\
\hline Underweight $(<18.5)$ & $2 \cdot 6$ & $1 \cdot 8,3 \cdot 8$ & 0.6 & $0 \cdot 2,1 \cdot 8$ & 4.6 & $3 \cdot 1,6 \cdot 9$ & $<0.001$ \\
\hline Normal (18.5-24.9) & 49.9 & $46 \cdot 5,53 \cdot 4$ & 45.5 & $40 \cdot 1,51 \cdot 0$ & $54 \cdot 4$ & $50 \cdot 2,58 \cdot 5$ & \\
\hline Overweight (25-29.9) & 33.3 & $30 \cdot 1,36 \cdot 6$ & $42 \cdot 7$ & $37 \cdot 4,48 \cdot 1$ & $24 \cdot 0$ & $20 \cdot 7,27 \cdot 6$ & \\
\hline Obese $(\geq 30)$ & $14 \cdot 1$ & $12 \cdot 1,16 \cdot 4$ & $11 \cdot 2$ & $8 \cdot 6,14 \cdot 6$ & $17 \cdot 0$ & $14 \cdot 2,20 \cdot 3$ & \\
\hline \multicolumn{8}{|l|}{ Tobacco smoking } \\
\hline Never & $45 \cdot 6$ & $42 \cdot 2,49 \cdot 1$ & $34 \cdot 1$ & $29 \cdot 0,39 \cdot 5$ & $57 \cdot 1$ & $52 \cdot 9,61 \cdot 1$ & $<0.001$ \\
\hline Current & 27.9 & $24 \cdot 9,31 \cdot 2$ & 31.6 & $26 \cdot 7,37 \cdot 0$ & $24 \cdot 3$ & $20 \cdot 8,28.2$ & \\
\hline Former & 26.5 & $23 \cdot 7,29 \cdot 4$ & $34 \cdot 3$ & $29.6,39.4$ & $18 \cdot 6$ & $15 \cdot 9,21 \cdot 7$ & \\
\hline Education & & & & & & & \\
\hline Up to high school & 63.0 & $59 \cdot 9,66 \cdot 0$ & $63 \cdot 2$ & $58 \cdot 2,67 \cdot 9$ & $62 \cdot 9$ & $59 \cdot 0,66 \cdot 6$ & 0.98 \\
\hline High school & $16 \cdot 1$ & $13 \cdot 8,18 \cdot 7$ & $15 \cdot 8$ & $12 \cdot 4,20 \cdot 0$ & $16 \cdot 3$ & $13 \cdot 4,19 \cdot 7$ & \\
\hline University graduate & 20.9 & $18 \cdot 8,23 \cdot 2$ & $21 \cdot 0$ & $17 \cdot 7,24 \cdot 7$ & 20.9 & $18 \cdot 2,23 \cdot 8$ & \\
\hline Alcohol use & & & & & & & \\
\hline No & $18 \cdot 3$ & $16 \cdot 0,20 \cdot 9$ & 9.4 & $7 \cdot 0,12 \cdot 5$ & $27 \cdot 2$ & $23 \cdot 6,31 \cdot 2$ & $<0.001$ \\
\hline Yes & 81.7 & $79 \cdot 1,84 \cdot 0$ & $90 \cdot 6$ & $87.5,93.0$ & $72 \cdot 8$ & $68 \cdot 8,76 \cdot 5$ & \\
\hline
\end{tabular}

${ }^{*} P$ values were calculated by design-based $t$ tests or $\chi^{2}$ tests as appropriate.

Table 5. Urine spot samples electrolyte concentrations and estimations of daily sodium intake and excreted in the application study ( $n$ 1720)

(Mean values and standard deviations)

\begin{tabular}{|c|c|c|c|c|c|c|c|}
\hline & \multicolumn{2}{|c|}{ All $(n$ 1720) } & \multicolumn{2}{|c|}{ Men ( $n$ 662) } & \multicolumn{2}{|c|}{ Women $(n$ 1058) } & \multirow[b]{2}{*}{$P \dagger$} \\
\hline & Mean & SD & Mean & SD & Mean & SD & \\
\hline \multicolumn{8}{|l|}{ Spot urine samples concentrations } \\
\hline $\mathrm{Na}(\mathrm{mmol} / \mathrm{l})$ & $93 \cdot 1$ & 1.5 & 101.5 & $2 \cdot 3$ & 84.7 & $1 \cdot 7$ & $<0.001$ \\
\hline $\mathrm{K} \ddagger(\mathrm{mmol} / \mathrm{l})$ & 31.4 & 0.9 & 35.5 & 1.5 & $27 \cdot 4$ & 0.7 & $<0.001$ \\
\hline Creatinine§ (mmol/l) & $11 \cdot 0$ & 0.2 & $12 \cdot 8$ & 0.3 & $9 \cdot 2$ & 0.3 & $<0.001$ \\
\hline \multicolumn{8}{|l|}{ Estimations from 24-h dietary recalls } \\
\hline Na intake $(\mathrm{mg} / \mathrm{d})$ & 3159 & 40 & 3681 & 59 & 2642 & 32 & $<0.001$ \\
\hline Salt equivalent $(g / d)$ & 8.0 & 0.1 & $9 \cdot 3$ & 0.1 & 6.7 & 0.1 & $<0.001$ \\
\hline \multicolumn{8}{|l|}{ Predictions from INTERSALT equationll } \\
\hline 24-hUNa excretedๆ (mmol/d) & 128.9 & $1 \cdot 0$ & $140 \cdot 7$ & 1.7 & $117 \cdot 2$ & 0.9 & $<0.001$ \\
\hline Equivalent in mg/d & 2965 & 23 & 3236 & 38 & 2696 & 21 & $<0.001$ \\
\hline 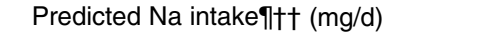 & 3188 & 25 & $3480^{\star *}$ & 41 & $2898^{\star \star *}$ & 22 & $<0.001$ \\
\hline Predicted salt equivalent $(\mathrm{g} / \mathrm{d})$ & $8 \cdot 1$ & 0.1 & $8 \cdot 8$ & 0.1 & 7.4 & 0.1 & $<0.001$ \\
\hline \multicolumn{8}{|l|}{ Corrected predictions $\ddagger \ddagger$} \\
\hline 24-hUNa excreted corrected $\mid(\mathrm{mmol} / \mathrm{d})$ & 147.4 & $1 \cdot 1$ & $159 \cdot 0$ & 1.9 & $135 \cdot 9$ & 1.0 & $<0.001$ \\
\hline Equivalent in mg/d & 3391 & 26 & 3657 & 43 & 3127 & 24 & $<0.001$ \\
\hline Predicted $\mathrm{Na}$ intake corrected $\emptyset(\mathrm{mg} / \mathrm{d})$ & $3646^{\star \star \star}$ & 28 & $3932^{\star \star \star}$ & 47 & $3362^{\star \star \star}$ & 26 & $<0.001$ \\
\hline Predicted salt equivalent corr $(\mathrm{g} / \mathrm{d})$ & $9 \cdot 3$ & 0.1 & $10 \cdot 0$ & 0.1 & 8.5 & 0.1 & $<0.001$ \\
\hline
\end{tabular}

24-hUNa, 24-h urinary sodium.

Difference between sodium intake estimated from 24-h dietary recalls and sodium intake predicted from INTERSALT equation (with and without calibration) was statistically

significant: ${ }^{* \star} P<0.01,{ }^{* \star *} P<0.001$ ( $t$ test).

† $P$ values were calculated by design-based $t$ tests or $\chi^{2}$ tests as appropriate.

$\ddagger n 1718$ (662 men/1056 women).

$\S n 1719$ (662 men/1057 women).

II Predictions from INTERSALT equation using spot urine samples.

If $n 1717$ (662 men/1055 women).

t† Predicted sodium intake was calculated using the following formula: $100 \times 24$-hUNa excreted/93; $93 \%$ is the percentage of sodium which is excreted in $24 \mathrm{~h}$ compared with sodium intake.

㧊 Corrected using calibration coefficient calculated in the validation study ( $13 \%$ for men and $16 \%$ for women). 
In the present validation study, while being significantly correlated ( $r$ 0.42; $P<0.001)$, prediction was underestimated by $14 \%$ compared with measured $24-\mathrm{hUNa}$ excretion. Results of previous studies using the INTERSALT equation showed fluctuations in the accuracy of predictions ${ }^{(16,18,36,37)}$, and some previous works also observed such an underestimation $^{(19,20,35,38)}$. To complement correlation coefficients, it is recommended to use a Bland-Altman analysis ${ }^{(9,34)}$ in validations studies. In our study, the mean bias (between measured and predicted 24-hUNa excretion) in Bland-Altman analysis was moderate $(19.2 \mathrm{mmol} / \mathrm{d})$ and comparable with that reported by Kelly et $a l .{ }^{(19)}$ for INTERSALT predictions based on morning urinary spots $(15 \mathrm{mmol} / \mathrm{d})$. Those results (significant correlation and moderate bias) show the possible use of the INTERSALT equation to predict 24-hUNa excretion from spot urine samples at a population level. They also provide calibration coefficients for the French population. However, similar to the results of Rhee et $a l .{ }^{(35)}$, the limits of agreement (from -61.4 to $99.7 \mathrm{mmol} / \mathrm{d}$ ) and the percentage error (greater than $60 \%$ ) show important variability around the mean difference and limit the use of this method at an individual level. So, our findings are consistent with the general consensus that spot urinary Na could be a useful alternative to $24-\mathrm{h}$ urine collection in populations but a poor predictor of 24-hUNa excretion in individuals ${ }^{(13,18,20-22,25,39)}$. This method may be useful to estimate global $\mathrm{Na}$ intake in the French population, but given the underestimation and the important variability, caution remains when using it for public health purposes. It can be used to estimate population-level salt intake in cross-sectional studies such as nationwide survey, and to adapt public health recommendations and actions, but its usefulness to evaluate actions may be limited by the relatively small changes in population salt intake that can be seen in response to populationlevel interventions over time ${ }^{(40)}$.

In the present validation study, correlations between predicted and measured 24-hUNa excretions ( $r 0.43$ for men and $r 0.34$ for women) were below than those previously published ${ }^{(16,18,20)}$. It can be explained by the difference in the urine collection times between our study (including only morning spots) and the others (with urinary spot samples collected at different times). Indeed, metabolic studies indicate that urinary $\mathrm{Na}$ excretion displays circadian variations, and that $\mathrm{Na}$ would be more excreted in the afternoon and evening ${ }^{(29,41,42)}$. Mann \& Gerber $^{(27)}$ showed that mean predicted 24-hUNa excretion from spot based on samples collected in the afternoon and evening was a more relevant approximation of real mean of 24-hUNa excretion compared with samples collected in the morning or overnight. In our study, although having two spots per participant in the validation study, all spot urine samples were collected in the morning due to protocol constraints. As mentioned in previous studies, the use of multiple spots, collected at different times of the day, would be a better indicator for predictions $(16,25,27,28)$

In the application study, we found an average intake of $3159 \mathrm{mg} / \mathrm{d}$ (equivalent to $\sim 8 \mathrm{~g} / \mathrm{d}$ of salt) using dietary recalls, which overestimates by $5.5 \%$ in men and underestimates by $9.7 \%$ in women compared with the INTERSALT predicted $\mathrm{Na}$ intake. The result obtained in women is consistent with another study which reported that $\mathrm{Na}$ intake measured from dietary recalls was subject to underestimation (about $10 \%$ for women and $7 \%$ for men in comparison with the Na biomarkers) ${ }^{(43)}$. This is not found in men in the present study. This could be explained by a better estimate of $\mathrm{Na}$ intake in dietary recalls in men compared with women, or by other factors that could lead to further $\mathrm{Na}$ losses. Indeed, different factors have been reported to affect estimates of $\mathrm{Na}$ excretion such as health status, circadian variations, hydration status or excessive sweating, and some behaviours such as vigorous physical activity or short-term exposure to high temperature were not measured in this study. Our results show, however, that the estimation of $\mathrm{Na}$ intake by dietary recalls is fairly accurate in men, but that it requires some improvements in women for whom $\mathrm{Na}$ intake is largely underestimated (by almost $10 \%$ in comparison with original INTERSALT prediction and by more than $27 \%$ when applying calibration coefficients).

A strength of this study was the use of two 24-h urine collections and two spot urine samples to carry out the validation study. Wang et al. ${ }^{(29)}$ reported important within-person variance in 24-h urines and timed spot urine samples (ranging from 16 to $29 \%$ and 21 to $41 \%$, respectively) of mean excretion, concluding that repeated measurements are necessary to overcome withinperson variation ${ }^{(28,44-46)}$. Another strength of this study was the use of three 24-h dietary recalls to estimate $\mathrm{Na}$ intake in general adult French population. Three 24-h dietary recalls have been reported to be optimal for estimating individual energy intake ${ }^{(47)}$. In general, the method used in the present study meets the majority of the recommendations for validation studies reported by McLean et $a l .{ }^{(9)}$ regarding the 24-h dietary recalls (multiple nonconsecutive days, inclusion of an estimate of discretionary salt used), the 24-h urine collections (multiple non-consecutive collections per participant, undertaken over the same period of assessment as the dietary assessment, with the use of a suitable method to measure completeness) and the statistical analysis (multiple methods used, including correlation and Bland-Altman methods and with a sample size carefully calculated). Finally, the NutriNetSanté and ENNS studies used for the present analysis are comparable, since these two studies employed the same methodology to assess dietary intake (the same 24-h dietary assessment instrument and a unique food composition table) and carried out their biological assays in the same laboratory.

However, some limitations should be noted. First, the timing of spot urine samples differed between the validation and application studies. In the validation study, morning spot urine samples were collected (likely not the first-morning urine as it was collected during the visit), while it was a first-morning urine spot sample (corresponding to overnight urine, collected at home) in the application study. Wang et al. ${ }^{(29)}$ showed that overnight specimens had lower $\mathrm{Na}$ concentrations compared with morning specimens; therefore, this difference of protocol may have contributed to underestimate the 24-hUNa predictions made in the application sample. However, the morning sample in the validation study was done in a fasting state and may not differ that much from an overnight sample. Second, only healthy volunteers were included in the validation study. Previous work has studied the non-representative nature of the overall sample of NutriNet-Santé study where women and well-educated individuals are over-represented compared with national data ${ }^{(48)}$. This volunteer bias was partly limited by the sampling strategy of 
the Dietary Validation Study. In addition, the ENNS showed that salt intake of French adults differed according to sex but not according to age or education level ${ }^{(49)}$. Third, the INTERSALT equation has been developed and validated in a relatively young population of adults (20-59 years) ${ }^{(16)}$ and recent work showed that this equation was not consistently valid for older adults ${ }^{(23)}$. However, the mean age was 50 years in the present validation study (age range 23-83 years), so caution is advised when extrapolating from the results of underestimation of the mean $\mathrm{Na}$ intake.

In summary, we found that dietary salt intake in French adults is high and above the WHO recommendations and that the use of a spot urine collection remains an acceptable alternative in monitoring and evaluating the $\mathrm{Na}$ level of the population by applying population-specific correction coefficients that we provide. However, spot urine samples are insufficient to estimate individual salt intake, and the 24-h urine collection remains the gold standard for $\mathrm{Na}$ intake assessment. Further research is needed to find more reliable methods of dietary assessment of salt intake.

\section{Acknowledgements}

The authors thank all the staff involved in this study: the dietitians, the nurses and physicians from the health examination centres of the French National Health Insurance System and the Cetaf (Centre Technique d'Appui et de Formation des Centres d'Examens de Santé).

The NutriNet-Santé Study was supported by the French Ministry of Health, Santé publique France (former Institut de Veille Sanitaire and Institut National de la Prévention et de l'Education pour la Santé), the Fondation pour la Recherche Médicale (FRM), the Institut National de la Santé et de la Recherche Médicale (INSERM), the Institut National de la Recherche Agronomique (INRA), the Conservatoire National des Arts et Métiers (CNAM) and the University of Paris 13. The Dietary Validation Study was funded by Santé publique France (former Institut de Veille Sanitaire) and supported by grants from the Région Ile de France (CORDDIM). The Etude Nationale Nutrition Santé (ENNS survey) was supported by Santé publique France (former Institut de Veille Sanitaire), the University of Paris 13 and the Caisse nationale d'Assurance maladie des Travailleurs salaries (CnamTS).

C. L., K. C., V. D., M. V., S. H., P. G. and E. K. G. designed the research; D. G. and P. F. carried out the biomarker analyses; E. E., B. S. and C. V. analysed the data and performed the statistical analysis; E. E. and C. V. wrote the initial draft; C. L., K. C., V. D., B. S., M. V., D. G., P. F., S. H., P. G. and E. K. G. modified and completed the manuscript. All authors read and approved the final manuscript.

The authors declare that there is no conflict of interest.

\section{References}

1. Aburto N, Ziolkovska A, Hooper L, et al. (2013) Effect of lower sodium intake on health: systematic review and meta-analyses. BMJ 346, f1326.

2. Chobanian A, Bakris G, Black H, et al. (2003) Seventh report of the Joint National Committee on prevention, detection, evaluation, and treatment of high blood pressure. Hypertension 42, 1206-1252.

3. He F, Li J \& Macgregor G (2013) Effect of longer term modest salt reduction on blood pressure: Cochrane systematic review and meta-analysis of randomised trials. BMJ 346, f1325.

4. Koliaki C \& Katsilambros N (2013) Dietary sodium, potassium, and alcohol: key players in the pathophysiology, prevention, and treatment of human hypertension. Nutr Rev 71, 402-411.

5. Mente A, O'Donnell M, Rangarajan S, et al. (2014) Association of urinary sodium and potassium excretion with blood pressure. N Engl J Med 371, 601-611.

6. Strazzullo P, D'Elia L, Kandala N, et al. (2009) Salt intake, stroke, and cardiovascular disease: meta-analysis of prospective studies. BMJ 339, b4567.

7. Mozaffarian D, Fahimi S, Singh G, et al. (2014) Global sodium consumption and death from cardiovascular causes. $N$ Engl J Med 371, 624-634.

8. World Health Organization (2007) Prevention of Cardiovascular Disease: Guidelines for Assessment and Management of Cardiovascular Risk. Geneva: WHO.

9. McLean RM, Farmer VL, Nettleton A, et al. (2018) Twenty-fourhour diet recall and diet records compared with 24-hour urinary excretion to predict an individual's sodium consumption: a systematic review. J Clin Hypertens 20, 1360-1376.

10. Lucko A, Doktorchik C, Woodward M, et al. (2018) Percentage of ingested sodium excreted in 24-hour urine collections: A systematic review and meta-analysis. J Clin Hypertens 20, 1220-1229.

11. Elliott P \& Brown I (2007) Sodium intakes around the world. Background document prepared for the Forum and Technical meeting on Reducing Salt Intake in Populations (Paris 5-7th October 2006). Geneva: WHO. http://www. who.int/dietphysicalactivity/Elliot-brown-2007.pdf (accessed October 2018).

12. Cogswell ME, Maalouf J, Elliott P, et al. (2015) Use of urine biomarkers to assess sodium intake: challenges and opportunities. Annu Rev Nutr 35, 349-387.

13. McLean RM (2014) Measuring population sodium intake: a review of methods. Nutrients $\mathbf{6}, 4651-4662$.

14. Kawasaki T, Itoh K, Uezono K, et al. (1993) A simple method for estimating $24 \mathrm{~h}$ urinary sodium and potassium excretion from second morning voiding urine specimen in adults. Clin Exp Pharmacol Physiol 20, 7-14.

15. Tanaka T, Okamura T, Miura K, et al. (2002) A simple method to estimate populational 24-h urinary sodium and potassium excretion using a casual urine specimen. J Hum Hypertens 16, 97-103.

16. Brown IJ, Dyer AR, Chan Q, et al. (2013) Estimating 24-hour urinary sodium excretion from casual urinary sodium concentrations in Western populations: the INTERSALT study. Am J Epidemiol 177, 1180-1192.

17. WHO/PAHO Regional Expert Group for Cardiovascular Disease Prevention through Population-wide Dietary Salt Reduction (2010) Protocol for population level sodium determination in 24-hour urine samples. https://www.paho.org/hq/ dmdocuments/2013/24h-urine-Protocol-eng.pdf (accessed October 2018).

18. Cogswell ME, Wang CY, Chen TC, et al. (2013) Validity of predictive equations for 24-h urinary sodium excretion in adults aged 18-39 y. Am J Clin Nutr 98, 1502-1513.

19. Kelly C, Geaney F, Fitzgerald AP, et al. (2015) Validation of diet and urinary excretion derived estimates of sodium excretion against 24-h urine excretion in a worksite sample. Nutr Metab Cardiovasc Dis 25, 771-779.

20. McLean R, Williams S \& Mann J (2014) Monitoring population sodium intake using spot urine samples: validation in a New Zealand population. J Hum Hypertens 28, 657-662. 
21. Zhou L, Tian Y, Fu JJ, et al. (2017) Validation of spot urine in predicting 24-h sodium excretion at the individual level. $\mathrm{Am}$ J Clin Nutr 105, 1291-1296.

22. World Health Organization (2011) Strategies to monitor and evaluate population sodium consumption and sources of sodium in the diet: report of a joint technical meeting convened by WHO and the Government of Canada. Geneva: WHO.

23. Allen NB, Zhao L, Loria CM, et al. (2017) The validity of predictive equations to estimate 24-hour sodium excretion: the MESA and CARDIA Urinary Sodium Study. Am J Epidemiol 186, 149-159.

24. Hooft van Huysduynen EJ, Hulshof PJ, van Lee L, et al. (2014) Evaluation of using spot urine to replace $24 \mathrm{~h}$ urine sodium and potassium excretions. Public Health Nutr 17, 2505-2511.

25. Ji C, Sykes L, Paul C, et al. (2012) Systematic review of studies comparing 24-hour and spot urine collections for estimating population salt intake. Rev Panam Salud Publica 32, 307-315.

26. Doenyas-Barak K, Beberashvili I, Bar-Chaim A, et al. (2015) Daily sodium and potassium excretion can be estimated by scheduled spot urine collections. Nephron 130, 35-40.

27. Mann SJ \& Gerber LM (2010) Estimation of 24-hour sodium excretion from spot urine samples. J Clin Hypertens 12, 174-180

28. Uechi K, Asakura K, Ri Y, et al. (2016) Advantage of multiple spot urine collections for estimating daily sodium excretion: comparison with two 24-h urine collections as reference. $J$ Hypertens 34, 204-214.

29. Wang CY, Cogswell ME, Loria CM, et al. (2013) Urinary excretion of sodium, potassium, and chloride, but not iodine, varies by timing of collection in a 24-hour calibration study. J Nutr 143, 1276-1282.

30. Lassale C, Castetbon K, Laporte F, et al. (2015) Validation of a web-based, self-administered, non-consecutive-day dietary record tool against urinary biomarkers. BrJ Nutr 113, 953-962.

31. Hercberg S, Castetbon K, Czernichow S, et al. (2010) The Nutrinet-Santé Study: a web-based prospective study on the relationship between nutrition and health and determinants of dietary patterns and nutritional status. BMC Public Health 10, 242.

32. Castetbon K, Vernay M, Malon A, et al. (2009) Dietary intake, physical activity and nutritional status in adults: the French nutrition and health survey (ENNS, 2006-2007). Br J Nutr 102, 733-743.

33. World Health Organization (1995) Physical status: the use and interpretation of anthropometry. Report of a WHO Expert Committee. WHO Technical Report Series, 8(54). Geneva: WHO.

34. Bland JM \& Altman DG (1986) Statistical methods for assessing agreement between two methods of clinical measurement. Lancet I, 307-310.

35. Rhee MY, Kim JH, Shin SJ, et al. (2014) Estimation of 24-hour urinary sodium excretion using spot urine samples. Nutrients 6, 2360-2375.
36. Mente A, O'Donnell MJ, Dagenais G, et al. (2014) Validation and comparison of three formulae to estimate sodium and potassium excretion from a single morning fasting urine compared to 24-h measures in 11 countries. J Hypertens 32, 1005-1014.

37. Polonia J, Lobo MF, Martins L, et al. (2017) Estimation of populational 24-h urinary sodium and potassium excretion from spot urine samples: evaluation of four formulas in a large national representative population. J Hypertens 35, 477-486.

38. Pfeiffer CM, Hughes JP, Cogswell ME, et al. (2014) Urine sodium excretion increased slightly among U.S. adults between 1988 and 2010. J Nutr 144, 698-705.

39. Conkle J \& van der Haar F (2016) The use and interpretation of sodium concentrations in casual (spot) urine collections for population surveillance and partitioning of dietary iodine intake sources. Nutrients $\mathbf{9}, 1$.

40. Cappuccio F \& D'Elia L (2018) Evaluating population salt reduction programmes worldwide: the risk of cutting corners! Public Health Nutr 21, 2161-2163.

41. Dyer AR, Martin GJ, Burton WN, et al. (1998) Blood pressure and diurnal variation in sodium, potassium, and water excretion. J Hum Hypertens 12, 363-371.

42. Stow LR \& Gumz ML (2011) The circadian clock in the kidney. $J$ Am Soc Nephrol 22, 598-604.

43. Rhodes DG, Murayi T, Clemens JC, et al. (2013) The USDA Automated Multiple-Pass Method accurately assesses population sodium intakes. Am J Clin Nutr 97, 958-964.

44. Iwahori T, Ueshima H, Miyagawa N, et al. (2014) Six random specimens of daytime casual urine on different days are sufficient to estimate daily sodium/potassium ratio in comparison to 7-day 24-h urine collections. Hypertens Res 37, $765-771$

45. Knuiman JT, Hautvast JG, van der Heijden L, et al. (1986) A multi-centre study on within-person variability in the urinary excretion of sodium, potassium, calcium, magnesium and creatinine in 8 European centres. Hum Nutr Clin Nutr 40, 343-8.

46. Liu K, Dyer AR, Cooper RS, et al. (1979) Can overnight urine replace 24-hour urine collection to asses salt intake? Hypertension 1, 529-536.

47. Ma Y, Olendzki BC, Pagoto SL, et al. (2009) Number of 24-hour diet recalls needed to estimate energy intake. Ann Epidemiol 19, 553-559.

48. Andreeva VA, Salanave B, Castetbon K, et al. (2015) Comparison of the sociodemographic characteristics of the large NutriNet-Santé e-cohort with French Census data: the issue of volunteer bias revisited. I Epidemiol Community Health 69, 893-898.

49. Unité de surveillance et d'épidémiologie nutritionnelle (2007) Etude nationale nutrition santé (ENNS, 2006). Situation nutritionnelle en France en 2006 selon les indicateurs d'objectif et les repères du Programme national nutrition santé (PNNS). Saint-Maurice: Institut de veille sanitaire. http://opac.invs.sante. fr/doc_num.php?explnum_id=3481 (accessed October 2018). 